\title{
The effect of verbal size information upon visual judgments of absolute distance
}

\author{
MAX COLTHEART \\ University of Waterloo, Waterloo, Ontario, Canada
}

When an $O$ views a blank triangle of light under completely reduced conditions, he is able to make use of verbally conveyed information about the size of this stimulus when he is attempting to judge the absolute distance of the stimulus. Although between-Os variance is rather large in this situation, group mean distance estimates are highly veridical. This is further evidence for the view that, when the $O$ is given a retinal subtense, any kind of information about size enables him to make a judgment of absolute distance, just as information about distance enables him to make a judgment of absolute size.

Ittelson (1951) and Hastorf (1950) claimed that when an object was viewed under completely reduced conditions, Os were able to make judgments of the absolute distance of the object if they had information about the size of the object contributed by past experience with the object. They claimed, in fact, that familiar size was one of the cues'to absolute distance. Their experiments were subsquently shown by Gogel, Hartman, and Harker (1957) to be methodologically inadequate, and for some time thereafter there was considerable dispute concerning the familiar-size cue to absolute distance.

It is now clear that judgments of absolute distance can be made on the basis of familiar size (Coltheart, 1968; Gogel, 1968, 1969; Gogel \& Mertens, 1967), although such judgments will be very variable and of marginal veridicality. Since familiarity is only one of a number of possible sources of size information, it is natural to consider whether other kinds of size information can also be used when Os are making visual judgments of absolute distance under reduced conditions. Coltheart (1969a) showed that information contributed by means of a haptically presented comparison object could be used by $O s$ when they were making judgments of absolute distance, although distance was markedly underestimated in this situation.

Instead of being communicated by familiarity or by means of a haptic comparison object, size information can be contributed verbally. An experiment of this kind was carried out by Baird (1963), who used three groups, each containing 10 Os. Each $O$ viewed an erect rectangle of light monocularly through a viewing tube against a black background. The stimulus was always $25 \mathrm{ft}$ from the $O$, and each $O$ was told by the $E$ that the stimulus was the same size as a foot ruler. For one group this was true; for another group the stimulus was actually half the size of a foot ruler; for the third group the stimulus was twice the size of a foot ruler. Each $O$ was

Table 1

Means and SDs of Distance Estimates for Each Group

Mean

\begin{tabular}{ccc} 
Instructions & Estimate (Feet) & SD \\
\hline 4 in. & 7.70 & 6.06 \\
8 in. & 13.72 & 6.17
\end{tabular}

asked to give an estimate in feet of the distance of the stimulus from him. If the verbal information presented to the $O$ had been utilized perfectly, the three groups would have given mean estimates of $25 \mathrm{ft}$, $50 \mathrm{ft}$, and $12.5 \mathrm{ft}$. The means that were actually obtained were $24.0 \mathrm{ft}, 48.2 \mathrm{ft}$, and $14.3 \mathrm{ft}$.

It is not clear that the source of size information used by Baird was one that had not been studied previously. Since the stimulus was described as a foot ruler, his Os may have been utilizing the familiar-size cue, rather than using verbal size information perse. In other words, these instructions might have served only to identify the stimulus with a familiar object, not to convey information directly about the size of the stimulus. In the experiment reported in this paper, verbal information and familiar size were not confounded in this way. The main aim of this experiment was to establish whether verbally imparted size information could be utilized under these conditions by Os attempting to make judgments of absolute distance, and, if so, whether the remarkable veridicality evident in Baird's data would still be obtained. This veridicality is all the more remarkable because distance judgments based on familiar size (Coltheart, 1968) or haptically imparted size (Coltheart, 1969a) markedly underestimate the true distance of the stimulus.

\section{METHOD}

Forty-six undergraduates at the University of Sydney served as Os. Each $\mathrm{O}$ was led blindfolded into a light-tight dark room, measuring $17 \times 32 \mathrm{ft}$, and seated in one corner. The blindfold was removed, and the $O$ sighted across toward the diagonally opposite corner of the room, using his preferred eye and looking through a monocular viewing tube in a Masonite screen. His line of sight passed through a $5 \times 3$ in. elliptical aperture in a reduction screen 36 in. from his eye.

Previous pilot research had demonstrated that residual distance cues were absent from this experimental situation; for example, stimuli differing greatly in physical distance but having the same retinal subtense were not judged to be at different distances, and no visible frame was formed around the stimulus by the end of the viewing tube.

Fourteen feet from the $O$ and at his eye level was the visual stimulus, a transilluminated equilateral triangle with 8 -in. sides, produced by cutting out a triangle from the opaque material masking the milk-glass screen of a light box.

Each $O$ was asked to estimate, in feet and inches, the distance of the triangle from him. Half of the Os were told by the $E$ that the triangle had 4-in. sides. The remaining $O s$ were told that the triangle had 8 -in. sides.

\section{RESULTS}

The means and standard deviations of the distance estimates of the two groups are shown in Table 1.

The means differ significantly $(t=3.27$, $\mathrm{df}=44, \mathrm{p}<.005)$ and neither mean differs from the value predicted if the verbal information were used perfectly, these values being 7.0 and $14.0 \mathrm{ft}$, respectively. Thus, remarkable accuracy in distance estimation was achieved by $O$ s who were basing their judgments upon verbal information concerning the size of the stimulus they were viewing. There was no indication of the severe underestimation of distance that occurs when size information is conveyed by means of familiarity or by means of a haptic comparison object.

Gogel $(1963,1964)$ argued that the large standard deviations which occurred in Baird's experiment (42.6, 7.3, and $5.6 \mathrm{ft}$ for the half-ruler, normal-ruler, and double-ruler groups) show that this kind of size cue could not be of much value because of its lack of precision. It is important to note, however, that these statistics are between-Os measures; they are not derived from repeated measurements of single Os, and, hence, individual differences will inflate the standard deviations. A particularly likely source of such individual differences is differences in the way in which Os use verbal estimates to describe apparent distance. The existence of such individual differences does not imply that the cue is an imprecise one; to show this, appreciable within-O variation would be required. Repeated measurements in this situation cannot be 
obtained; if the stimulus situation remains unchanged, there is no reason for the $\mathbf{O}$ to vary his response, and if different stimuli are used, the $\mathrm{O}$ will make relative rather than absolute judgments (Gogel, 1969). Thus, there seems no way of settling the question of the precision with which Os can make distance judgments based upon verbally imparted size information.

From these results and from the results of Coltheart (1968, 1969a), it is clear that visual judgments of absolute distance can be based on size information whether it is conveyed verbally, haptically, or by familiarity. Coltheart (1969b) found that visual judgments of absolute size can be based on distance information conveyed verbally or by familiarity. These findings lend further support to the general viewpoint that judged size, judged distance, and retinal subtense are interrelated in such a way that an $O$ equipped with information (however obtained) about any two of these factors is able to make judgments about the third.

BAIRD, J. C. Retinal and assumed size cues as determinants of size and perceived distance. Journal of Experimental Psychology, 1963, 66, 155-162.

COLTHEART, M. Size information as a factor in visual judgments of absolute distance under reduced conditions. Unpublished $\mathrm{PhD}$ thesis, University of Sydney, 1968.

COL THEART, M. The influence of haptic size information upon visual judgments of absolute distance. Perception \& Psychophysics, 1969a, $5,143-144$.

COLTHEART, M.-Effects of two kinds of distance information on visual judgments of absolute size. Nature, 1969b, 221, 383.

GOGEL, W. C. The visual perception of size and distance. Vision Research, 1963, 3, 101-120.

GOGEL, W. C. Size cue to visually perceived distance. Psychological Bulletin, 1964, 62, 217-235.
GOGEL, W. C. The effect of set on perceived egocentric distance. Acta Psychologica, 1968, $28,283-292$.

GOGEL, W. C. The absolute and relative size cues to distance. American Journal of Psychology, 1969, 82, 228-234.

GOGEL, W. C., HARTMAN, B. O., \& HARKER, G. S. The retinal size of a familiar object as a determiner of apparent distance. Psychological Monographs, 1957, 71, No. 442.

GOGEL, W. C., \& MERTENS, H. W. Perceived size and distance of familiar objects. Perceptual \& Motor Skills, 1967, 25, 213-225.

HASTORF, A. H. The influence of suggestion on the relation between stimulus size and perceived distance. Joumal of Psychology, 1950, 29, 195-217.

ITTELSON, W. H. Size as a cue to distance: Static localization. American Journal of Psychology, 1951, 64, 54-67.

(Accepted for publication July 6, 1970.) 